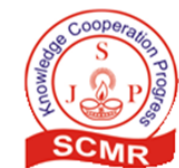

\title{
Estimation of Areal Changes along the Coastline of Bangladesh due to Erosion and Accretion
}

\author{
G. M. Jahid Hasan* and Naila Matin, \\ Department of Civil Engineering, Military Institute of Science and Technology, Dhaka, \\ Bangladesh
}

(Received 30 May 2019, accepted 14 October 2019)

https://doi.org10.36224/ijes.120305

\begin{abstract}
The present study focuses on the entire coastline of Bangladesh, which was analyzed for the last thirty years, with a five years' interval in between, to identify the changes in the shoreline position due to erosion or accretion. Shoreline positions for the time period 1989-2019, were manually digitized using multi-temporal Landsat satellite images of $30 \mathrm{~m}$ resolution and comparable tidal conditions. A polygon-based approach was then employed in Arc GIS to determine the areal changes in the three different exposed coastal zones. The central zone was found to be the most dynamic in terms of both erosion and accretion. The western zone was mostly characterized by erosion, whereas only the eastern zone experienced a net land gain in this time span. Periodic reversal from erosion or accretion was also noted in several locations. The outcome of this study regarding the general trend (erosional or depositional) along the coastline, is expected to aid the proper planning and land management of the coastal zones in Bangladesh.
\end{abstract}

Keywords: Coastal erosion-accretion, Shoreline changes, Landsat images, GIS, Bangladesh

\section{Introduction}

The shoreline of Bangladesh is well-known for its dynamic nature. Combined with the general low elevation of the coastlands, this tendency of frequent shoreline movement makes the coastline of Bangladesh exceptionally vulnerable. Severe events like cyclones, coastal flooding, sea level rise, and more regular phenomena such as waves, tidal currents, storms etc., are causing continuous changes to this deltaic shoreline through coastal erosion and accretion. Considering the significant impact the eroded and accreted area have on the coastal ecosystem, habitats, tourism, lives and properties of people, a detailed study on the shoreline changes for the entire coast of Bangladesh is much needed. Previously Sarwar and Woodroffe [1] conducted a study covering the whole coast, however the comparison of coastline change was between only two years and the time span between those years was very large to represent the actual scenario. Other such similar studies concerning erosion-accretion, were confined to only parts of the whole coast $[2,3,4]$. In the present study, it was aimed to conduct a comprehensive analysis of the changing shoreline for the entire coast of Bangladesh, using a set of multitemporal Landsat imageries, with a short interval of time in between (five years). Through this consistent monitoring of the coastline, the outcome of this study can be very useful in improving the general understanding of the morphological behavior of near shore coastal processes, which is a prerequisite for a better coastal zone management. 


\section{Study area}

In this study, the entire southern coast of Bangladesh has been considered, excluding only the islands that are separated from the mainland. The coast extends from Hariabhanga River (along the India-Bangladesh border) to Naf River (along the Myanmar-Bangladesh border), running parallel to the Bay of Bengal and forming a $710 \mathrm{~km}$ long coastline [5]. The southern coastal area of Bangladesh can be divided into three distinct regions based on geo-morphological features: the southwest Ganges Tidal Plain, the southcentral Meghna Delta Plain and the southeast Chittagong Coastal Belt, more commonly referred to as western, central and eastern zones [6] respectively as shown in Fig. 1.

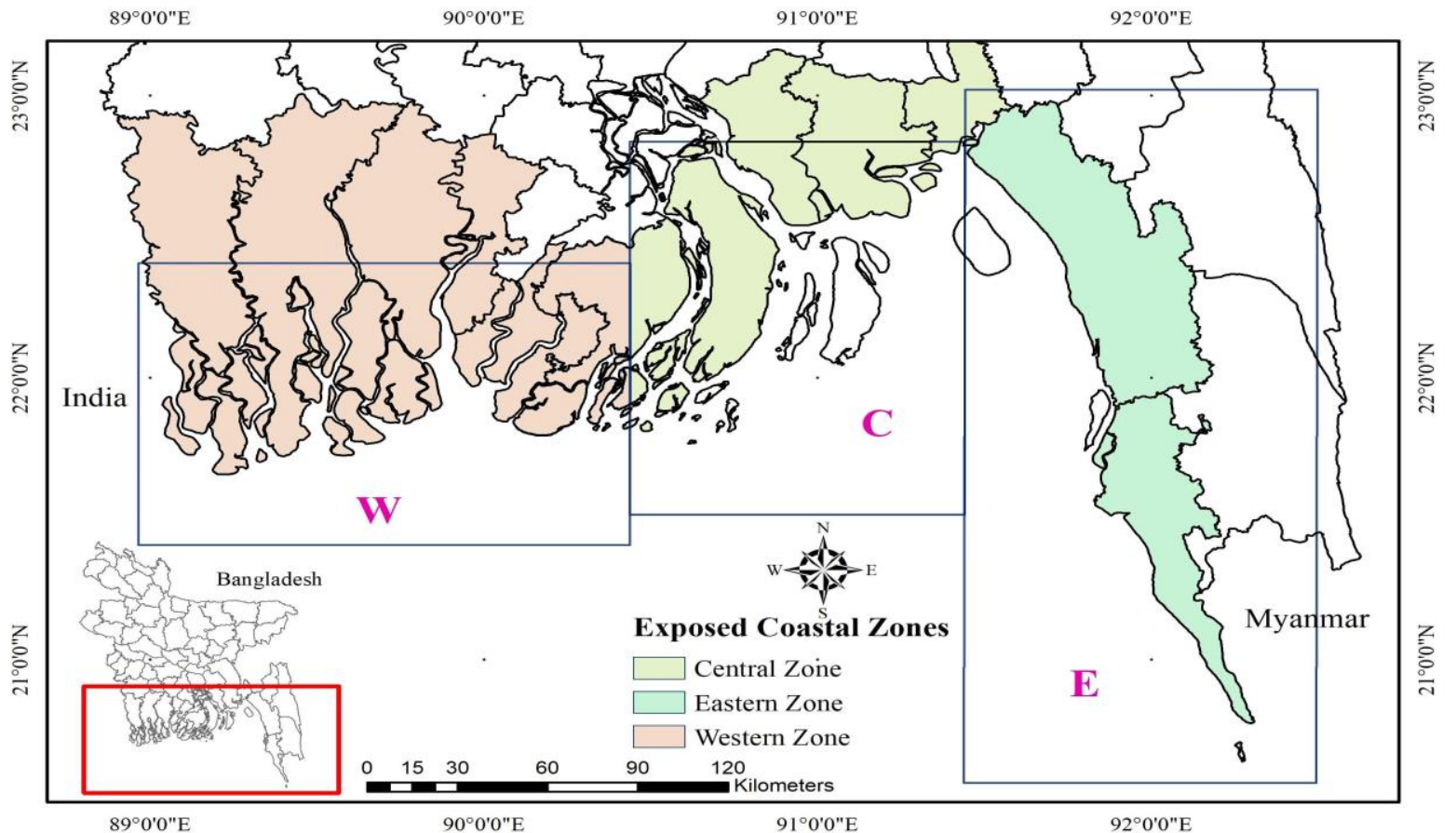

Figure 1: Coastal zones of Bangladesh, hereafter referred to as western, central and eastern zones

A total of 19 districts make up the coastal zones of Bangladesh, covering an area of approximately $47,201 \mathrm{~km}^{2}$ which is about a third of the total landmass of the country and provides shelter and livelihood to almost 46 million people [6, 7]. Out of these 19 districts, 12 districts have parts (locally called upazilas) that are directly facing the sea and/or the Lower Meghna estuary and these are considered the 'first tier of coastal upazilas', with the other upazilas located behind them. This zone is referred to as the exposed coast [8] and the interaction with the marine environment is most intense there. The present study focused on this exposed portion of the coastal zones, extending from latitude $22.82^{\circ} \mathrm{N}$ to $20.74^{\circ} \mathrm{N}$, and longitude $89.04^{\circ} \mathrm{E}$ to $92.35^{\circ} \mathrm{E}$. This region of exposed coast is highly vulnerable to environmental hazards and natural disasters but at the same time it provides irreplaceable socio-economic and ecological benefits to the country. 


\section{Data and methodology}

\subsection{Collection of Satellite Images}

Landsat images of $30 \mathrm{~m}$ resolution were collected for the period ranging from 1989 to 2019, with an interval of 5 years. For each year, six scenes of Landsat imagery covering the complete coast of Bangladesh were collected from the Earth Explorer database of USGS. Images were primarily collected for the months of January and February to ensure lesser cloud cover and hence clear visibility along the coast, so that the shoreline could be delineated accurately.

\subsection{Check for Tidal Condition}

In order to correctly observe the change of shoreline, the satellite images for each year must represent the similar tidal conditions. Unless all the images correspond to identical tidal

Table 1: Tidal characteristics during the Landsat images' acquisition times

\begin{tabular}{|c|c|c|c|c|c|c|c|}
\hline \multirow{2}{*}{$\begin{array}{c}\text { Spacecraft } \\
\text { Identifier }\end{array}$} & \multicolumn{2}{|c|}{ Landsat Scene } & Acquisition Date & $\begin{array}{c}\text { Acquisition } \\
\text { Time (GMT) }\end{array}$ & $\begin{array}{c}\text { BIWTA } \\
\text { Station }\end{array}$ & $\begin{array}{c}\text { Tide } \\
\text { Level } \\
(\mathrm{m})\end{array}$ & $\begin{array}{c}\text { Tidal } \\
\text { Condition }\end{array}$ \\
\cline { 2 - 3 } & Path & Row & & $4: 04$ AM & Khepupara & 1.28 & Low Tide \\
\hline LANDSAT_5 & 137 & 45 & 29.12 .2003 & $3: 57$ AM & Sandwip & 0.78 & Low Tide \\
\hline LANDSAT_5 & 136 & 44 & 08.02 .2004 & $3: 57$ AM & Cox's Bazar & 0.72 & Low Tide \\
\hline LANDSAT_5 & 136 & 45 & 27.03 .2004 & 0.72 &
\end{tabular}

condition (i.e. all images acquired during either low tide or high tide), shoreline change detection over the years will be largely erroneous, especially in regions of very gentle slope like the eastern coastal zones. To avoid such errors, the tidal stages for all images were verified by noting the time of capture of satellite image and water level records collected by Bangladesh Inland Water Transport Authority (BIWTA) at that time. Low tide condition was adopted as the benchmark and images showing good agreement in terms of tidal condition were finalized. Images that represented high tide condition were discarded and replaced with new suitable satellite images. For this, an extensive search of the Earth Explorer database was conducted also for the months of November, December and March whenever needed, if cloud-free, tidesynchronous images were not available for January and February. Table 1 shows the tidal checks performed for the year 2004 as an example.

As majority of the shoreline are covered by three scenes of Landsat (Path-Row: 137-45, 13644, 136-45), tide level check is done for only those scenes, whereas the remaining scenes (PathRow: 138-45, 137-44, 135-46) cover small sections of the coast, that are not covered by the three principal images.

\subsection{Shoreline Delineation and Area Calculation}

In this study shoreline was detected from a single short-wave infrared band of image as it exhibits strong reflectance by soil and vegetation and absorbance by water $[9,10]$. Band 5 of Landsat 4-5 TM and Landsat 7 ETM+ $(1.55-1.75 \mu \mathrm{m})$ and band 6 of Landsat 8 OLI/TIRS $(1.56-1.66 \mu \mathrm{m})$ was thus used, to clearly visualize the separation of land surface from water. Satellite images obtained from USGS were georeferenced and projected in WGS84 UTM zone-46 datum. Any further georeferencing was thus not required.

Manual digitization method was used to extract the shoreline from single band images by tracing along the land-water separation line. Mouths of small rivers and tidal creeks were 
connected by straight lines across them. Total areal changes (erosion/accretion) in different coastal sections was then calculated using a polygon-based approach in ArcGIS.

\section{Results and discussion}

For the three different coastal zones, net erosion and net accretion area were calculated for each five-year period, starting from 1989 to 2019. Table 2 summarizes the detailed results of calculation of eroded, accreted and net change of area for different time spans and Fig. 2 illustrates the changes in a comprehensible graphical form. From Fig. 2 it is evident that the central zone has been the most dynamic in terms of erosion/accretion for the last thirty years, experiencing significant erosion and accretion at the same time. On the other hand, the western zone seems to have been the most stable, while in the eastern zone the trend of net accretion shifted towards a trend of net erosion. Time series changes in coastal land area are denoted in Fig. 3, showing the spatial distribution of erosion and accretion for all the intervals. The general

Table 2: Land area subjected to erosion/accretion in various coastal zones for the period of 1989-2019

\begin{tabular}{|cccccccccc|}
\hline Year & \multicolumn{3}{c}{ Western Zone } & \multicolumn{3}{c}{ Central Zone } & \multicolumn{3}{c|}{ Eastern Zone } \\
\cline { 2 - 10 } & $\begin{array}{c}\text { Erosion } \\
\left(\mathrm{km}^{2}\right)\end{array}$ & $\begin{array}{c}\text { Accretion } \\
\left(\mathrm{km}^{2}\right)\end{array}$ & $\begin{array}{c}\text { Net land } \\
\text { gain/loss } \\
\left(\mathrm{km}^{2}\right)\end{array}$ & $\begin{array}{c}\text { Erosion } \\
\left(\mathrm{km}^{2}\right)\end{array}$ & $\begin{array}{c}\text { Accretion } \\
\left(\mathrm{km}^{2}\right)\end{array}$ & $\begin{array}{c}\text { Net land } \\
\text { gain/loss } \\
\left(\mathrm{km}^{2}\right)\end{array}$ & $\begin{array}{c}\text { Erosion } \\
\left(\mathrm{km}^{2}\right)\end{array}$ & $\begin{array}{c}\text { Accretion } \\
\left(\mathrm{km}^{2}\right)\end{array}$ & $\begin{array}{c}\text { Net land } \\
\text { gain/loss} \\
\left(\mathrm{km}^{2}\right)\end{array}$ \\
\hline $1989-94$ & 13.60 & 5.11 & -8.50 & 22.08 & 56.24 & 34.15 & 5.39 & 41.54 & 36.15 \\
\hline $1994-99$ & 23.20 & 2.77 & -20.43 & 24.59 & 58.92 & 34.33 & 23.67 & 35.47 & 11.80 \\
\hline $1999-04$ & 5.42 & 14.49 & 9.07 & 31.24 & 29.97 & -1.27 & 7.04 & 26.18 & 19.14 \\
\hline $2004-09$ & 11.88 & 3.35 & -8.53 & 43.92 & 39.75 & -4.17 & 17.14 & 8.27 & -8.87 \\
\hline $2009-14$ & 7.03 & 6.82 & -0.21 & 67.61 & 5.45 & -62.16 & 19.11 & 10.81 & -8.30 \\
\hline $2014-19$ & 13.24 & 1.22 & -12.02 & 65.26 & 2.98 & -62.28 & 28.35 & 7.53 & -20.82 \\
\hline Total & 74.39 & 33.77 & -40.62 & 254.70 & 193.30 & -61.40 & 100.71 & 129.80 & 29.09 \\
\hline
\end{tabular}

* ‘+' sign indicates land gain and '-' sign indicates land loss

trend of coastline movements was found consistent with previous studies performed on parts of the coast of Bangladesh [1, 3, 11]. In the following sections, changes observed in the different coastal zones are described.

\subsection{Western Zone}

In the western zone neither erosion nor accretion was overtly dominant. Net land gain or loss was well within $20 \mathrm{~km}^{2}$ for all the five-years long sessions except for the period 1994-1999. Maximum erosion of $23.2 \mathrm{~km}^{2}$ in this zone, was also observed in this period. Only one session ended with a net land gain, which was $9.07 \mathrm{~km}^{2}$, in the period 1994-2004. The least changes in land area was found in 2009-14 period, with almost nil net gain or loss, as erosion and accretion nearly equaled each other. In all the other intervals the zone was subjected to moderate erosion ranging around $11 \sim 13 \mathrm{~km}^{2}$ and very negligible accretion $\left(1 \sim 3 \mathrm{~km}^{2}\right)$, resulting in an average net land loss rate of about $2 \mathrm{~km}^{2} /$ year. The most notable changes in this zone was observed at Patharghata, where a total of almost $10 \mathrm{~km}^{2}$ of land was eroded and at Dublar Char, that experienced an accretion of almost $3.7 \mathrm{~km}^{2}$ in the period 1989-2019 (Fig. 3). 


\subsection{Central Zone}

Net land growth was found to be the prevailing trend in the central zone up to the year 1999, with average accretion being about $57 \mathrm{~km}^{2}$ in every five years. The time periods that followed (1999-2004 and 2004-09), there was very minimal net land loss, although both accretion and erosion were significantly high. In the last two time periods, there was drastic net land loss, exceeding $60 \mathrm{~km}^{2}$ in each period. From Fig. 2 it is apparent, that the rate of erosion steadily.

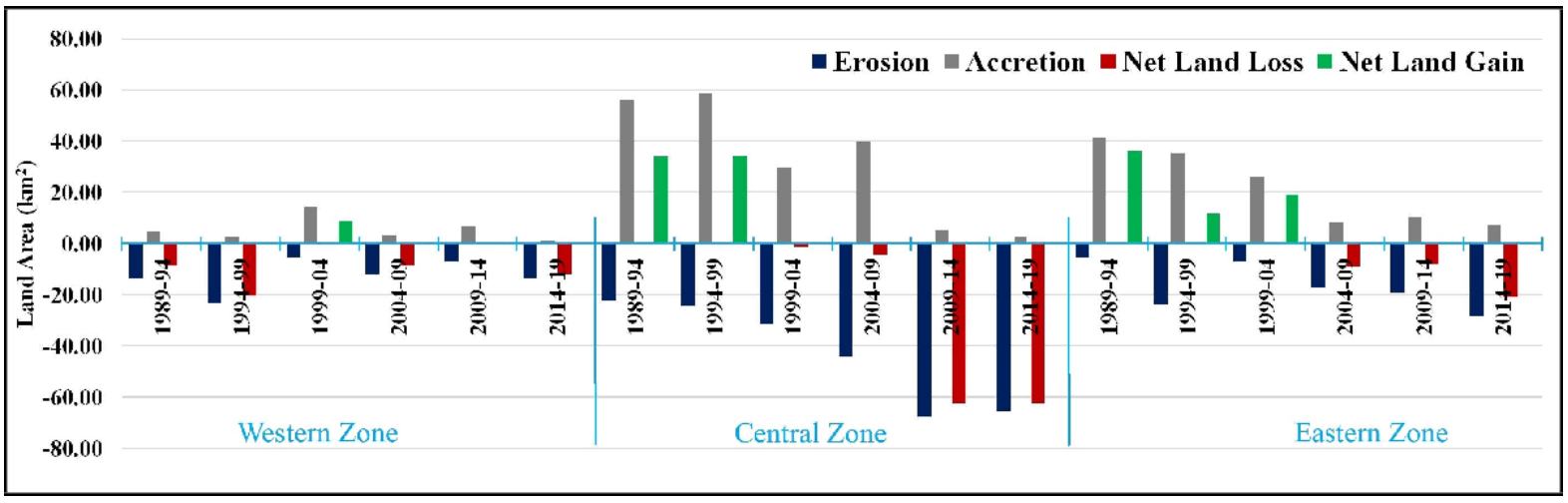

Figure 2: Erosion/Accretion in various coastal zones for the period of 1989-2019

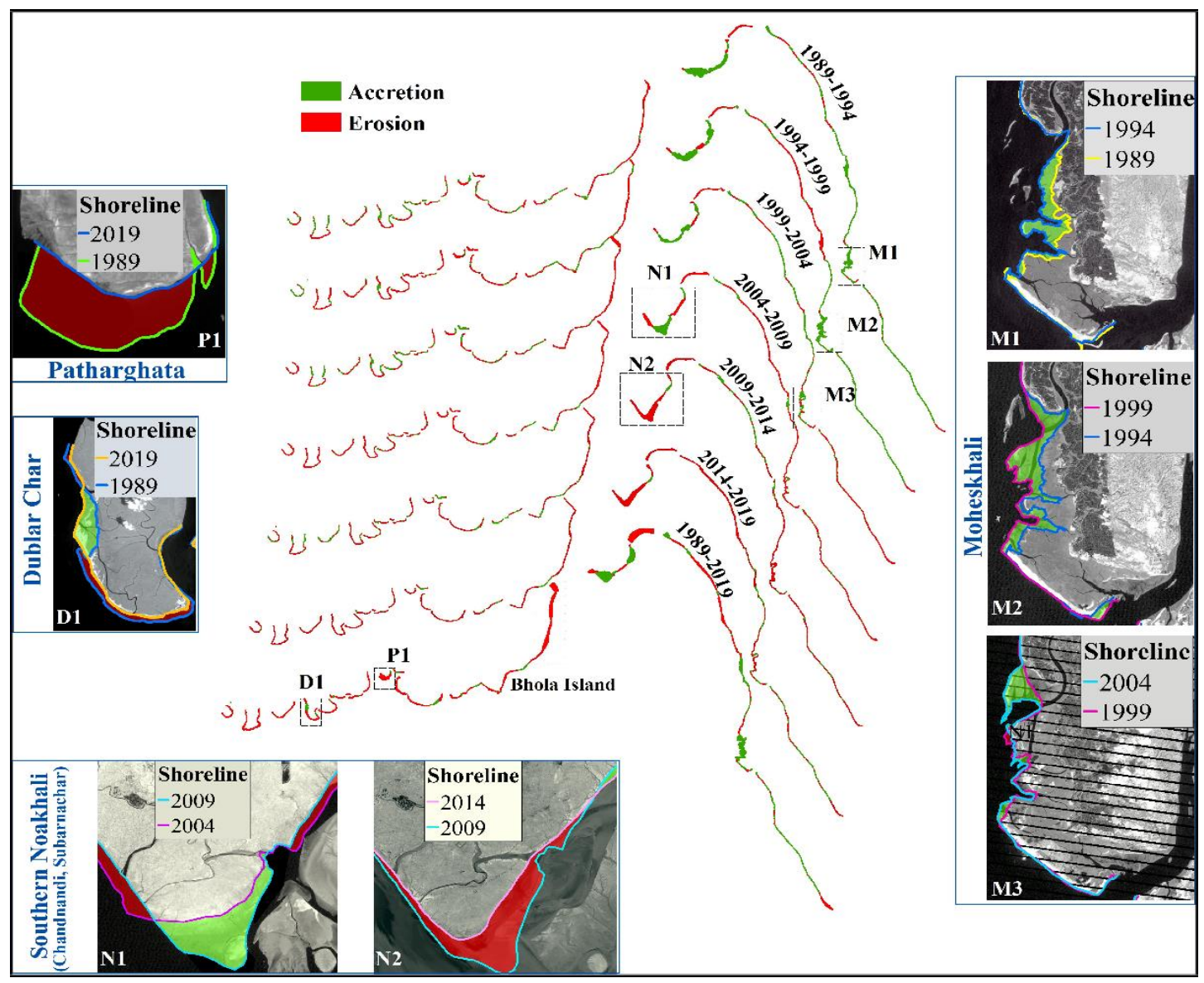

Figure 3: Change in land area along the coastline of Bangladesh from 1989 to 2019 
increased over all the time periods but the accretion rate substantially declined after 2009. Almost $90 \%$ of the immense accretion occurring in this zone in the first four time periods were in the southern part of Noakhali district (Fig. 3). Just in this region of Chandnandi and Subarnachar $56.5 \mathrm{~km}^{2}$ of land was accreted in the period 1994-1999, of the total $58.92 \mathrm{~km}^{2}$ land accretion in the central region. After 2009 the erosion increased to about $47 \mathrm{~km}^{2}$ while the accretion reduced to about $2 \mathrm{~km}^{2}$ in every five years. Another noteworthy areal change in this zone was observed at Bhola Island (Fig. 3). The island encountered a net land loss of 70 $\mathrm{km}^{2}$ in the thirty-year period.

\subsection{Eastern Zone}

A trend similar to the central zone was observed here, however the magnitude of erosion and accretion was comparably lower. Up until the year 2004, accretion was predominant in this zone, the highest being $41.54 \mathrm{~km}^{2}$. These first three time intervals resulted in a total land gain of $67.09 \mathrm{~km}^{2}$, much of which occurred around Moheshkhali Island (Fig. 3). In the remaining three time periods $(2004-09,2009-14,2014-19)$ the accretion decreased to an average of $8 \sim 10 \mathrm{~km}^{2}$, whereas the erosion gradually increased, reaching a peak of 28.35 $\mathrm{km}^{2}$ in the 2014-19 period. The distribution of erosion/accretion was quite irregular for the southern portion in these time intervals with shoreline movement always being within $200 \mathrm{~m}$ per five years, but this excludes the tip near Teknaf, where continuous erosion was observed over all the intervals.

\section{Conclusion}

The objective of this study was to investigate the areal changes along the coastline of Bangladesh in the previous three decades due to erosion and accretion. The three coastal zones exhibited different trend of shoreline change over the years and the magnitude of erosion/accretion also varied greatly. The western zone experienced the least changes, which was followed by the eastern zone and central zone respectively. Although accretion occurred significantly in a few localized areas, a more extensive part of the coast was dominated by erosional tendency, resulting in a considerable retreat of the shoreline, which requires sincere attention of the concerning authority. The historic areal changes of the coastal zones determined in this study is hoped to aid the implementation of effective shoreline management plans to combat the ever-increasing vulnerability of the coastlands of Bangladesh.

\section{Acknowledgement}

This research was undertaken as part of a coastal erosion hazard assessment project, funded by the Ministry of Science and Technology, People's Republic of Bangladesh and also Military Institute of Science and Technology (MIST). The authors gratefully acknowledge their patronage. 


\section{References}

1. Sarwar, M. G. M., \& Woodroffe, C. D., Rates of shoreline change along the coast of Bangladesh. Journal of Coastal Conservation, 2013,17,3, 515-526

2. Anwar, M. S., \& Takewaka, S., Analyses on phenological and morphological variations of mangrove forests along the southwest coast of Bangladesh, Journal of coastal conservation, 2014,18,4,339- 357

3. Rahman, A. F., Dragoni, D., \& El-Masri, B., Response of the Sundarbans coastline to sea level rise and decreased sediment flow: A remote sensing assessment, Remote Sensing of Environment, 2011,115, 12, 3121-3128

4. Mahamud, U., \& Takewaka, S., Shoreline Change around a River Delta on the Cox's Bazar Coast of Bangladesh, Journal of Marine Science and Engineering,2018, 6,3: 80

5. CZPo, Coastal Zone Policy, Ministry of Water Resources, Government of the People's Republic of Bangladesh, Dhaka, 2005

6. Karim, M. F., \& Mimura, N., Impacts of climate change and sea-level rise on cyclonic storm surgefloods in Bangladesh, Global Environmental Change,2008, 18,3, 490-500

7. WARPO, Coastal development strategy. Water Resources Planning Organization (WARPO), Ministry of Water Resources, Government of the People's Republic of Bangladesh, Dhaka, 2006

8. WARPO, Delineation of the coastal zone Program Development Office for Integrated Coastal Zone Management Plan (PDO-ICZMP). Water Resources Planning Organization (WARPO), Ministry of Water Resources, Government of the People's Republic of Bangladesh, Dhaka, 2003

9. Kuleli, T., Quantitative analysis of shoreline changes at the Mediterranean Coast in Turkey Environmental monitoring and assessment, 2010, 167,387-397

10. Alesheikh, A. A., Ghorbanali, A., \& Nouri, N., Coastline change detection using remote sensing, International Journal of Environmental Science \& Technology, 2007, 4,1, 61-66

11.Islam, M. A., Mitra, D., Dewan, A., \& Akhter, S. H., Coastal multi-hazard vulnerability assessment along the Ganges deltaic coast of Bangladesh-A geospatial approach, Ocean \& Coastal Management, 2016,127,1-15 